\title{
Measuring the specific surface area of snow with X-ray tomography and gas adsorption: comparison and implications for surface smoothness
}

\author{
M. Kerbrat ${ }^{2}$, B. Pinzer ${ }^{1}$, T. Huthwelker ${ }^{2}$, H. W. Gäggeler ${ }^{2,3}$, M. Ammann² ${ }^{2}$ and M. Schneebeli ${ }^{1}$ \\ ${ }^{1}$ WSL, Swiss Federal Institute for Snow and Avalanche Research SLF, Davos, Switzerland \\ ${ }^{2}$ Paul Scherrer Institute, 5232 Villigen PSI, Switzerland \\ ${ }^{3}$ University of Berne, 3012 Bern, Switzerland
}

Received: 14 June 2007 - Published in Atmos. Chem. Phys. Discuss.: 17 July 2007

Revised: 13 November 2007 - Accepted: 11 January 2008 - Published: 4 March 2008

\begin{abstract}
Chemical and physical processes, such as heterogeneous chemical reactions, light scattering, and metamorphism occur in the natural snowpack. To model these processes in the snowpack, the specific surface area (SSA) is a key parameter. In this study, two methods, computed tomography and methane adsorption, which have intrinsically different effective resolutions - molecular and $30 \mu \mathrm{m}$, respectively-were used to determine the SSA of similar natural snow samples. Except for very fresh snow, the two methods give identical results, with an uncertainty of $3 \%$. This implies that the surface of aged natural snow is smooth up to a scale of about $30 \mu \mathrm{m}$ and that if smaller structures are present they do not contribute significantly to the overall SSA. It furthermore implies that for optical methods a voxel size of $10 \mu \mathrm{m}$ is sufficient to capture all structural features of this type of snow; however, fresh precipitation appears to contain small features that cause an under-estimation of SSA with tomography at this resolution. The methane adsorption method is therefore superior to computed tomography for very fresh snow having high SSA. Nonetheless, in addition to SSA determination, tomography provides full geometric information about the ice matrix. It can also be advantageously used to investigate layered snow packs, as it allows measuring SSA in layers of less than $1 \mathrm{~mm}$.
\end{abstract}

\section{Introduction}

Snow, after sedimentation of the snow flakes on the surface, has a very high initial porosity and sinters rapidly. Specific surface area (SSA) is commonly used to describe sintered

Correspondence to: M. Schneebeli

(schneebeli@slf.ch) materials (German, 1996). In the context of integral geometry, specific surface area is identical to the second Minkowski functional (Ohser and Mücklich, 2000). Recently, SSA was found to be a monotonously decreasing parameter apart from volume fraction (Flin et al., 2004; Schneebeli and Sokratov, 2004; Legagneux and Dominé, 2005; Taillandier et al., $2007)$ in the course of snow metamorphism. This is in contrast to the traditionally used grain size, which has a nonmonotonous behaviour in the transition from fresh snow to rounded grain snow to depth hoar (Colbeck et al., 1990). Grenfell and Warren (1999) show that the ratio of volume to surface area (i.e. the inverse of SSA) is the best estimator for grain size in modelling optics. The same result but with a different optical theory is obtained by Kokhanovsky and Zege (2004). The air permeability of snow can be described using the Carman-Kozeny relation, which uses SSA in developing the hydraulic diameter (Dullien, 1992). Flanner and Zender (2006) use SSA to parameterize snow albedo in the context of global climate models. The interactions between the lower atmosphere and the snowpack is subject to extensive research and it is clear that the chemical reactions which take place in the snowpack depend heavily on the available surface i.e. on the SSA (Grannas et al., 2007). SSA is therefore one of the key parameters in snow physics and chemistry and a precise and unambiguous measurement is necessary.

The SSA of snow has been measured using various techniques, such as determining the adsorption isotherm of nitrogen (Adamson and Dormant, 1966; Adamson et al., 1967; Jellinek and Ibrahim, 1967; Hoff et al., 1998), or of methane at liquid nitrogen temperature (Chaix et al., 1996; Legagneux et al., 2002; Dominé et al., 2007b), via the grain size distribution (Granberg, 1985), with stereological measurements (Narita, 1971; Sommerfeld and Rocchio, 1993; Matzl and

Published by Copernicus Publications on behalf of the European Geosciences Union. 

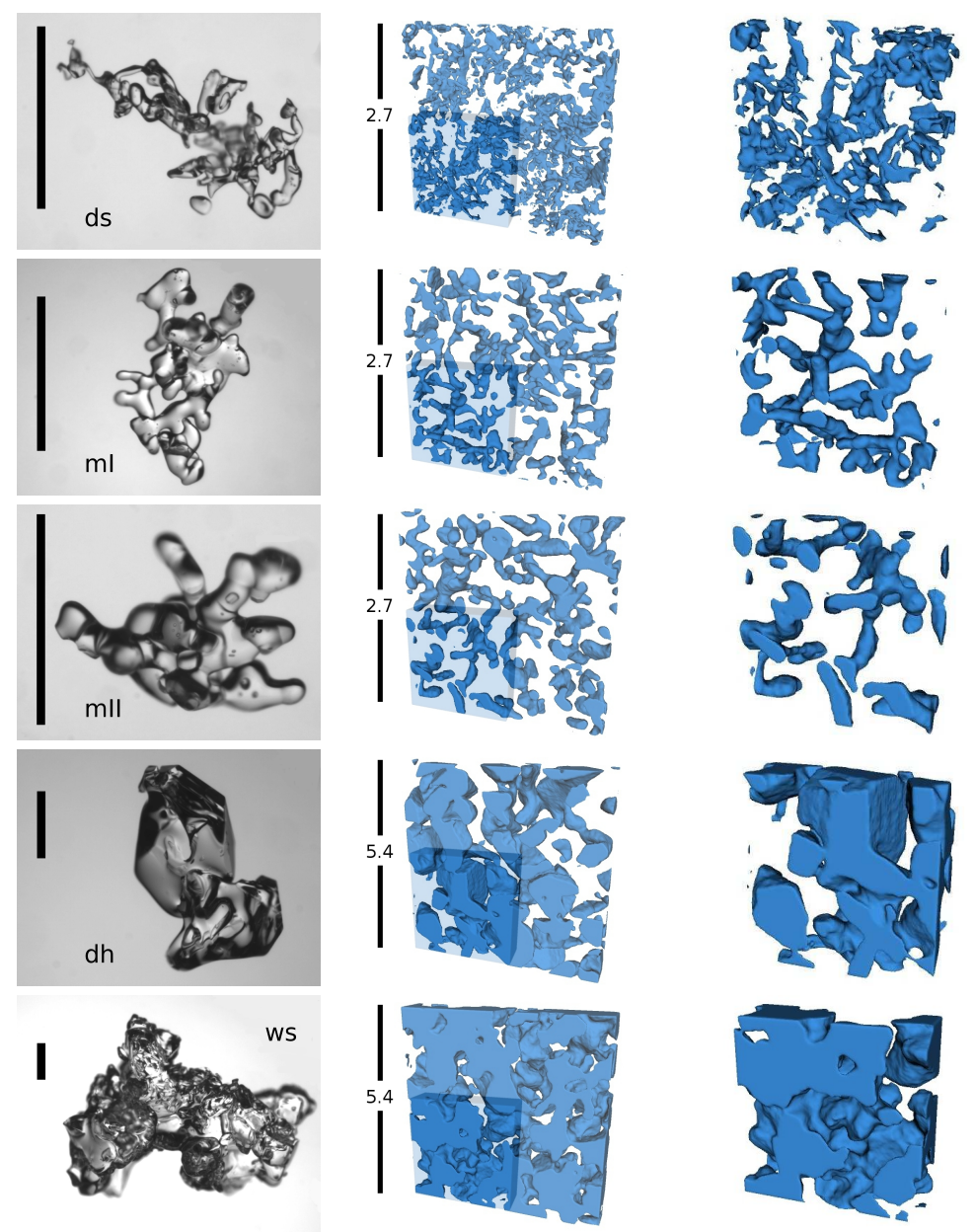

Fig. 1. Typical grain forms and corresponding 3-D-structures of the different snow types (from top to bottom): decomposing snow, metamorphosed I, metamorphosed II, depth hoar, and wet snow. The scale bar in the left column is always $1 \mathrm{~mm}$. In the middle column, note the different scales of the 3 -D volumes shown for fine grained $\left(2.7 \times 2.7 \times 0.45 \mathrm{~mm}^{3}\right)$ and coarse grained $\left(5.4 \times 5.4 \times 0.9 \mathrm{~mm}^{3}\right)$ snow types. The right column shows a detail of the 3 -D structure, i.e. the shaded lower left corner.

Schneebeli, $2007^{1}$ ), geometrical analysis of images of single snowflakes (Fassnacht et al., 1999), optical and electron microscopy (Dominé et al., 2001), and micro tomography (Flin et al., 2004; Schneebeli and Sokratov, 2004).

Previously published data show considerable scatter, reported values range from 6 up to $77700 \mathrm{~cm}^{2} \mathrm{~g}^{-1}$. This is not surprising, because the SSA strongly depends on snow history and snow type. In previous studies, snow history was not specified accurately; it is therefore almost impossible to compare the data obtained with the different techniques. On the other hand, an upper limit of SSA in natural snow covers may be estimated by considering the finest ice structures reaching the ground, so called diamond dust (Grenfell and Warren, 1999). These atmospheric long hexagonal ice crystals can

\footnotetext{
${ }^{1}$ Matzl, M. and Schneebeli, M.: Stereological measurement of the specific surface area of snow, J. Microscopy, submitted, preprint at http://www.slf.ch/schnee-lawinen/Schneephysik/Downloads/ Stereological_measurement_specific_surf_area.pdf, 2007.
}

have an aspect ratio of 50:1, with a typical diameter as small as $15 \mu \mathrm{m}$ and a length of $750 \mu \mathrm{m}$. Based on this shape, we estimate a geometric SSA of around $3500 \mathrm{~cm}^{2} \mathrm{~g}^{-1}$. However, some of the diamond dust was reported to be hollow, rising the SSA further to values around $6000 \mathrm{~cm}^{2} \mathrm{~g}^{-1}$. Snow in a natural snow cover must clearly have lower SSA, and this fact questions some of the early measurements which resulted in far too high values. Legagneux et al. (2002) explain that very high SSA values obtained in pioneer measurements using adsorption methods are due to the formation of amorphous ice during an inadequate cooling procedure. During the last ten years, the reported snow SSA seemed to converge to values between $20 \mathrm{~cm}^{2} \mathrm{~g}^{-1}$ and $1600 \mathrm{~cm}^{2} \mathrm{~g}^{-1}$, depending on the snow type (e.g. Dominé et al., 2007b; Chaix et al., 1996; Legagneux et al., 2002; Flin et al., 2004; Schneebeli and Sokratov, 2004). High SSAs are obtained on fresh snow whereas low SSAs are generally measured on aged refrozen snows. Note that values greater than $1000 \mathrm{~cm}^{2} \mathrm{~g}^{-1}$ are scarce. 
These measurements show that (i) SSA of snow varies over two orders of magnitude and (ii) a conclusive statement concerning the precision and value of the different methods is not possible without using identical snow samples.

Here, we compared - using identical snow samples two of the previously cited methods, namely adsorption of methane and X-ray Computed Micro-Tomography $(\mu \mathrm{CT})$. Methane adsorption measurements followed by BET analysis (Brunauer et al., 1938) have been intensively performed to assess this parameter and a large SSA dataset of natural snow was obtained using this technique (e.g. Dominé et al., 2007b; Legagneux et al., 2002). $\mu$ CT has also been successfully employed in the last decade to investigate geometrical properties of the ice structure and the pore space in snow (Coléou et al., 2001; Flin et al., 2004; Schneebeli and Sokratov, 2004). These techniques have also drastically different spatial resolutions. Methane adsorption measurement allows the calculation of accessible surface area from the number of adsorbed molecules and thus has a molecular resolution, whereas the used $\mu \mathrm{CT}$ reconstructs the spatial distribution of ice and air with a voxel size of $10 \mu \mathrm{m}$, which means that, after filtering, structures of about $30 \mu \mathrm{m}$ can be clearly resolved. By using two methods having such a different spatial resolution, we also want to address the question of the surface roughness of the ice surface of a snow crystal and the presence of microstructures on its surface. If microstructures exist, the large ratio between the resolutions of the two methods will lead to a disagreement of the measured SSA.

The presence and the size of surface microstructure in high vapour pressure condensed matter, such as ice, is determined by thermodynamic and kinetic processes. Minimization of the Free Energy reduces the overall surface area of the porous medium by sintering. On the contrary, continuous sublimation and resublimation of water molecules on the ice surface may induce roughening of the surface and hence the formation of new nanosized structures on the ice surface. The magnitude of such effects depends on the complex interplay of sublimation and resublimation rates, surface and bulk diffusion (Xiao and Ming, 1994). Additional complications occur, because at temperatures above about $-20^{\circ} \mathrm{C}$, as typical for natural snow, the ice surface is covered by a disordered surface region, which is often called premelt or quasi-liquid layer (see Dash et al., 2006, and citations therein). Because this layer is highly mobile, one might speculate that its thickness defines the scale of the smallest structures on the ice surface. At $-5^{\circ} \mathrm{C}$, the thickness is of the order of 1 to $10 \mathrm{~nm}$ (Henson et al., 2005; Dash et al., 1995; Lied et al., 1994), hence the smallest structures on the ice surface should be larger than this size.

Surface microstructures have been reported on natural snow by Rango et al. (1996) and Wergin et al. (2002) who presented scanning electron microscopy (SEM) images of rimed precipitation particles and irregular snow crystals, respectively. Similar microstructures have been seen by Dominé et al. (2003) with the same technique, but they ex- plain some of them as artefacts due to the resublimation of humid air during the transfer of the samples, which had been stored at liquid nitrogen temperature, into the SEM sample chamber. Nonetheless, even if those observations were artefacts, they show that microstructures can easily form at low temperature. The existence of micro-and nanostructures may affect physical processes, such as the growth of ice crystals (Libbrecht, 2005, and citations therein). Also, as microstructures would change the total surface area available for trace gas adsorption and chemical reactions on the ice surface, microstructures may also affect the chemical properties of snow.

In this paper, we show that both methods coincide within $3 \%$ for SSA ranging from 50 to $700 \mathrm{~cm}^{2} \mathrm{~g}^{-1}$. Therefore the physical concepts, on which the adsorption of methane and $\mu \mathrm{CT}$ are based, allow assessing the SSA of natural snow. It also shows that the low spatial resolution of the tomograph compared to an adsorption measurement is enough to measure accurately SSA of aged natural snow having an SSA lower than $700 \mathrm{~cm}^{2} \mathrm{~g}^{-1}$. Moreover, it indicates that the ice surface of snow in the settled snow pack is smooth up to a scale of $30 \mu \mathrm{m}$ under alpine conditions.

\section{Measurement procedure}

\subsection{Sampling}

We used five different natural snow types, covering the ranges $2-5$ defined in the International Classification for Seasonal Snow on the Ground (ICSSG) (Colbeck et al., 1990). These are expected to cover a broad range of SSA. Three types of snow, called "decomposing snow" $(d s)$, "metamorphosed I" $(m I)$, and "metamorphosed II" $(m I I)$, were prepared by sieving (in order to avoid creation of inhomogeneities) fresh snow after precipitation into boxes. The boxes were stored at different temperatures, allowing for isothermal metamorphism at different rates. Details of storage are found in Table 2. Two more snow types were collected in the field just before the measurements, denoted "depth hoar" $(d h)$, and large grained "wet snow" (ws). The dh snow was collected in blocks, while the ws was also sieved into boxes (10 mm grid) and soaked with ice water to further reduce the SSA. These snow types $d s, m I, m I I, d h$, and ws, correspond to the ICSSG classes $2 \mathrm{a}, 3 \mathrm{a} / 2 \mathrm{a}, 3 \mathrm{a}, 5 \mathrm{a}_{2}$, and $6 \mathrm{a}$, respectively (see Table 2 ). The characteristic grain shapes, along with the real 3-D structures, of all five snow types are shown in Fig. 1.

Natural snow covers exhibit density fluctuations and layering on a length scale of various centimeters (Matzl and Schneebeli, 2006). Since homogeneity of the snow used for sampling is crucial for comparison of the two methods, we confirmed homogeneity for each block of snow by means of a high resolution penetrometer (Schneebeli et al., 1999). In the region of maximum homogeneity, 7 to 8 cores, each of 


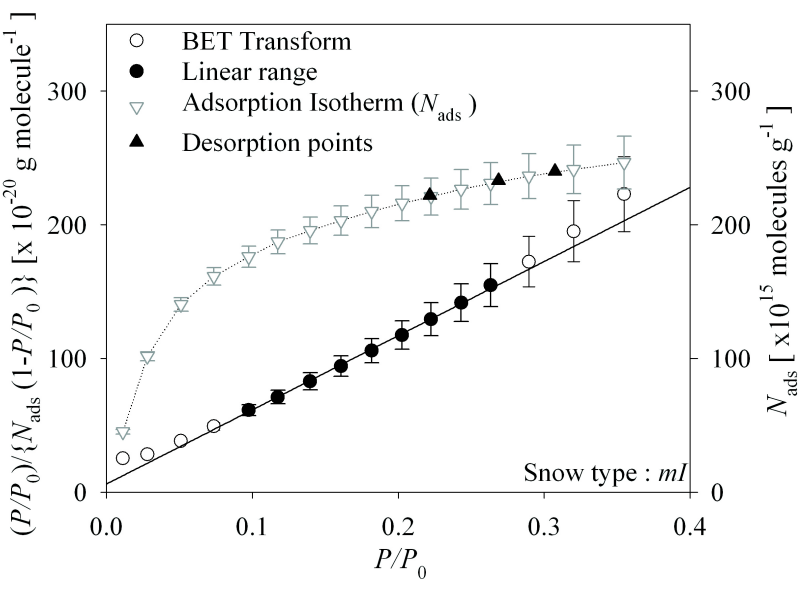

Fig. 2. The BET transform (in black on the left axis), is derived from the isotherm of adsorption (in grey on the right axis) (Brunauer et al., 1938). The slope and the intercept of the linear part are used to calculate the SSA (Legagneux et al., 2002).

$57.3 \mathrm{~cm}^{3}$ volume, were extracted by inserting sharp edged Polyethyleneimine (PEI) sample holders into the snow and carefully removing the remaining snow at the outside of the sample holders. After weighing each cylinder, five cylinders were mounted in a specially designed stainless steel sample holder for the BET measurements, while the remaining samples were directly scanned in the $\mu \mathrm{CT}$.

\subsection{Adsorption of methane}

\subsubsection{Analytical method}

In this study, we used the apparatus already used by BartelsRausch et al. (2002, 2004). The adsorption method to determine the SSA of snow using methane has been described by Legagneux et al. (2002). In short, a small amount of gaseous methane is filled into a defined volume called introduction volume $\left(V_{i}\right)$. Methane is then expanded into the evacuated sample holder kept at liquid nitrogen temperature, which contains the snow. The pressure drop, due to expansion of the gas into the sample holder and the methane adsorption on the snow surface allows calculating the number of molecules which have adsorbed on the snow surface. This number is calculated using the ideal gas equation. It is assessed from the difference in the gas phase molar budget of methane before and after the expansion. An isotherm of adsorption is obtained by increasing the pressure of methane over snow step by step.

\subsubsection{Measurement protocol}

All measurements were made according to a strict protocol as follows. i) The snow sample is thermalized to liquid nitrogen temperature for at least 1 hour. ii) The air is very slowly evacuated from the porous snow sample $\left(\approx 5 \mathrm{~mL} \mathrm{~min}^{-1}\right)$ us- ing first a primary pump and subsequently a turbo molecular pump. After around 30 minutes, high vacuum $\left(\approx 10^{-2} \mathrm{~Pa}\right)$ is established in the system. The vapour pressure of ice at liquid nitrogen temperature is lower than $4.2 \times 10^{-12} \mathrm{~Pa}$ (lowest value calculated in Murphy and Koop, 2005, at $111 \mathrm{~K}$ ). Hence, sublimation of ice due to pumping is insignificant. iii) The empty volume or dead volume $\left(V_{d}\right)$ i.e. the volume not occupied by the snow sample is measured, at least three times, by expanding Helium into the snow filled sample holder. Although the u-shaped gas inlet is immersed into liquid nitrogen, the flow of helium was kept at a slow rate of $6 \times 10^{16}-3 \times 10^{17}$ Molecules s ${ }^{-1}$ to avoid possible annealing of the snow sample due to the introduction of warm gas. iv) The isotherm of adsorption was measured. Sixteen data points were recorded by stepwise increasing the reduced pressure $\left(P_{n} / P_{0}\right)$ of methane over snow, where $P_{n}$ is the pressure of methane in the system after the $\mathrm{n}$ th expansion and $P_{0}$ is the vapour pressure of methane at liquid nitrogen temperature. v) Three desorption points were recorded to check the reversibility of the adsorption.

Each isotherm obtained was processed by applying the BET model (Brunauer et al., 1938; Legagneux et al., 2002; Gregg and Sing, 1982). This model describes the adsorption of gases in multimolecular layers. Assuming that an infinite number of layers is formed during the adsorption process, the model leads to

$\frac{P_{n} / P_{0}}{N_{\mathrm{ads}_{n}}\left(1-P_{n} / P_{0}\right)}=\frac{1}{N}{ }_{M C}+\frac{C-1}{N_{M} C} \frac{P_{n}}{P_{0}}$,

where $N_{\mathrm{ads} n}$ is the number of molecules adsorbed per gram of snow after the $\mathrm{n}$ th methane injection, $P_{n}$ is the pressure in the system, $P_{0}$ is the vapour pressure of methane at liquid nitrogen temperature, $N_{M}$ is the monolayer capacity (i.e. the total number of molecules that can be adsorbed on a single layer) and $C$ is the so called BET constant.

\subsubsection{Error calculation}

The reproducibility of the adsorption method using methane at liquid nitrogen temperature was carefully checked by Legagneux et al. (2002) who measured an overall accuracy of $12 \%$. We used the same method and an apparatus practically identical to the one used by Legagneux et al. (2002). The overall accuracy of our measurements is therefore also of about $12 \%$. Nonetheless, in extension to the work done by Legagneux et al. (2002), we checked the "a-priori error" of the method i.e. we evaluated the error on the measured SSA values resulting (i) from errors of the experimental devices used for the analysis and (ii) from errors on the physico-chemical data used for the evaluation of the adsorption isotherms. The details of the calculation are given in appendix A. As seen in Eqs. (A2) and (A4), the SSA is obtained from the slope $(S)$ and the intercept $(I)$ of the BET transform (Eq. 1), and from the size of the methane molecule on ice at liquid nitrogen temperature $\left(\mathrm{a}_{\mathrm{CH}_{4}}\right)$. The error on 
Table 1. Parameters used for the analysis of the adsorption measurements together with their inherent errors.

\begin{tabular}{|c|c|c|c|c|}
\hline Symbol & Quantity & Unit & Origin of the error & Error Value \\
\hline$A$ & Avogadro Number & $\mathrm{mol}^{-1}$ & {$[-]$} & {$[-]$} \\
\hline$a_{\mathrm{CH}_{4}}$ & Molecular area of $\mathrm{CH}_{4}$ adsorbed on ice & $\mathrm{m}^{2}$ & $\mathrm{ED}$ & $5 \%$ \\
\hline$I$ & Intercept of the BET transform & g molecule ${ }^{-1}$ & \multicolumn{2}{|c|}{ Fit of the experimental data } \\
\hline$m_{\text {ice }}$ & Masse of the snow sample & $\mathrm{g}$ & IR & $0.3 \mathrm{~g}$ \\
\hline$P_{0}$ & Vapour Pressure of $\mathrm{CH}_{4}$ at $T_{C}$ & $\mathrm{~Pa}$ & PCD \& ED & $2 \mathrm{~Pa}$ \\
\hline$P_{n}$ & Pressure in $V_{i}$ after the $n$-th injection & $\mathrm{Pa}$ & IR & $0,1 \mathrm{~Pa}$ \\
\hline$P_{n}^{\prime}$ & Pressure in $V_{i}$ before the $n$-th injection & $\mathrm{Pa}$ & IR & $0,1 \mathrm{~Pa}$ \\
\hline$R^{n}$ & Gas constant & $\mathrm{J} \mathrm{K}^{-1} \mathrm{~mol}^{-1}$ & {$[-]$} & {$[-]$} \\
\hline$S$ & Slope of the BET transform & g molecule ${ }^{-1}$ & \multicolumn{2}{|c|}{ Fit of the experimental data } \\
\hline$T_{c}$ & Liquid Nitrogen temperature & $\mathrm{K}$ & $\mathrm{PCD} \& \mathrm{ED}$ & $0,2 \mathrm{~K}$ \\
\hline$T_{h_{n}}$ & Temperature of $V_{i}$ after the $n$-th injection & $\mathrm{K}$ & IR & $0,1 \mathrm{~K}$ \\
\hline$T_{h_{n}}^{\prime \prime}$ & Temperature of $V_{i}$ before the $n$-th injection & $\mathrm{K}$ & IR & $0,1 \mathrm{~K}$ \\
\hline$V_{d}$ & Dead Volume & $\mathrm{m}^{3}$ & \multicolumn{2}{|c|}{ Determined for each measurement } \\
\hline$V_{e h}$ & Part of the expansion volume at the temperature $T_{h_{n}}$ & $\mathrm{~m}^{3}$ & ED & $9 \times 10^{-7}$ \\
\hline$V_{i}$ & Introduction volume & $\mathrm{m}^{3}$ & ED & $7 \times 10^{-7}$ \\
\hline
\end{tabular}

ED: Experimental Determination, IR: Instrumental Resolution, PCD: Pysico-Chemical Data.

the determination of the SSA is therefore connected to those values. Figure 3 shows the evolution of the relative error on SSA $(\triangle \mathrm{SSA} / \mathrm{SSA})$ as a function of the SSA. It can be seen that $\triangle$ SSA/SSA slightly increases with the SSA. This observation is correlated with the fact that $I$ and $S$ decrease as the SSA increases. Indeed, the relative error on $I$ and $S, \Delta \mathrm{I} / \mathrm{I}$ and $\Delta \mathrm{S} / \mathrm{S}$, respectively-which were obtained from uncertainties while fitting the BET transform-increase as $I$ and $S$ decrease. This results in an increase of $\triangle \mathrm{SSA} / \mathrm{SSA}$ with the SSA. On a first glance, this result may look somehow surprising as, in general, for any measurement method, increased accuracy is expected with a rise of the measured quantity. Indeed, when measuring the BET isotherm, with a higher number of adsorbed molecules, the pressure difference can be more accurately measured and the error on each data point of the isotherm will be smaller - after the same number of injections - for a high SSA sample compared to a low SSA sample. However, as explained before, the BET model (through the couple of variables $I$ and $S$ ) is more deeply involved in the SSA calculation and therefore in the error calculation. The steepness of the BET transform seems to be a more important issue when considering the "apriori errors" on SSA.

The error on each data point of the isotherms was obtained from estimating the error propagation following the same method as the one used for calculating $\triangle \mathrm{SSA}$. The inherent errors of the parameters involved when calculating the number of adsorbed molecules, and therefore the BET transform (Eq. 1), are given in Table 1. The equation allowing calculating the number of adsorbed molecule -in unit of molecules $\mathrm{g}^{-1}$-from the pressure difference is similar to the one given by Legagneux et al. (2002). To allow an easy connection with

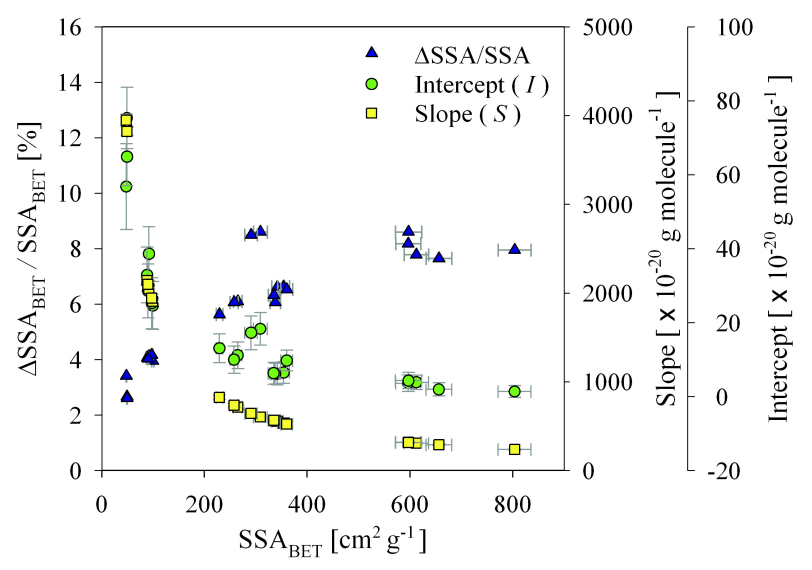

Fig. 3. The "a-priori error" on the measured SSAs for the adsorption method strongly depends on uncertainties on the slope $(S)$ and the intercept $(I)$ of the BET transform (Eq. 1). Those uncertainties, generated while fitting the BET transform, increase as their values decrease, which results in an anti-correlation between $\triangle$ SSA/SSA and $I$ and $S$.

the symbols given in Table 1 and the equation, it is recalled in Appendix A (Eq. A1).

As seen in Fig. 2 , due to the repetitive injections of methane "a-priori errors" on the data points of the BET transform are increasing with rising methane pressure. In order to take this increase into account when fitting the BET transform of the isotherm, each data point was assigned a weight equal to the inverse of its own error.

The calculated "a-priori errors" (below 10\%) are consistent with the one measured by Legagneux et al. (2002) (12\%). 


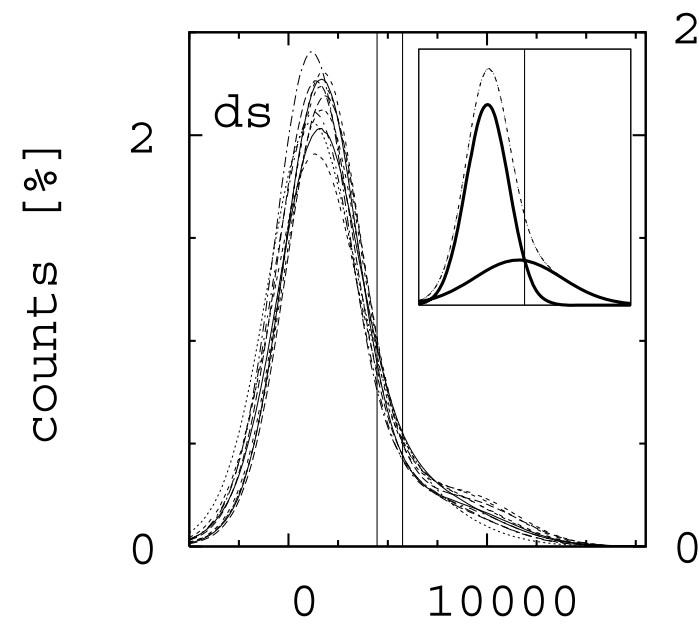

grayscale value

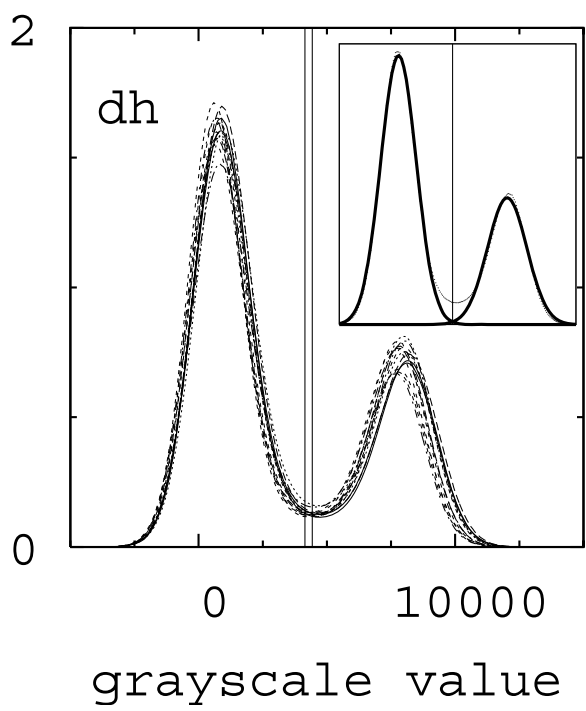

Fig. 4. Histograms of the filtered 3-D greyscale tomography images. Shown are all tomograms for decomposing snow and depth hoar. The fraction of "mixed voxels" is much higher for decomposing snow $(d s)$ than for depth hoar $(d h)$. The bars are located at plus and minus one standard deviation of the mean optimum threshold of the individual measurements. The inserts show the underlying individual gaussian distributions for one example histogram per snow type.

\subsubsection{Liquid Nitrogen Temperature}

The measurements were done in Davos, Switzerland, where, due to the altitude, the atmospheric pressure in the laboratory was $828( \pm 4) \mathrm{hPa}$ during the experiments. The boiling point temperature of liquid nitrogen at this pressure was derived to be $75.7( \pm 0.2) \mathrm{K}$ (Moussa et al., 1966). The vapour pressure of methane at $75.7 \mathrm{~K}$ was calculated to be $1030( \pm 2) \mathrm{Pa}$ (Lide, 2006).

\subsection{Tomography}

We used a modified Scanco $\mu$ CT 80 desktop X-ray computer tomograph, with a microfocus $\mathrm{X}$-ray source emitting a white spectrum ( $45 \mathrm{kV}$ acceleration voltage), to scan the snow samples. A $180^{\circ}$ rotation of the sample was divided into 1000 steps. At each angular step, a $1024 \times 128$ CCD detector captured the absorption signal during an integration time of $250 \mathrm{~ms}$, and averaged over two such intervals in order to reduce the noise. The apparatus resides in a cold room at $-15^{\circ} \mathrm{C}$. With this configuration, a complete scan with 408 slices took approximately $3 \mathrm{~h}$. Along with each adsorption measurement, two or three tomograms were taken, with a voxel size of $10 \mu \mathrm{m}$ for the fine grained $d s, m I$, and $m I I$ snow types. This corresponds to the maximum resolution of the $\mu \mathrm{CT}$. For the much coarser dh and $w s$ types a resolution of $18 \mu \mathrm{m}$ was chosen, since then a larger volume can be processed. After scanning, a subvolume was extracted from the reconstructed image. After filtering with a $3 \times 3 \times 3$ median filter and a $3 \times 3 \times 3$ 3-D Gaussian kernel filter with a standard deviation of 1.2 voxels a volume of $600 \times 600 \times 400$ voxels remains. Hence, the investigated volumes correspond to
$144 \mathrm{~mm}^{3}$ and $840 \mathrm{~mm}^{3}$ for a voxel size of respectively 10 and $18 \mu \mathrm{m}$, which can be considered representative for the whole sample. This has been shown by Kaempfer et al. (2005) and Coléou et al. (2001), who found that the elementary volumes, i.e. the minimal volumes which correctly represent the bulk snow properties, are between $1.25^{3}$ and $2.5^{3} \mathrm{~mm}^{3}$, depending on the snow coarseness. The volumes we have used for the analysis are at least ten times larger.

To segment the images we considered the grey scale histograms of the tomograms. Figure 4 shows the histograms of all measurements of two snow types, decomposing snow and depth hoar. One would expect two peaks, representing the two materials ice and air; while this is true for depth hoar, the histogram for decomposing snow is dominated by the air peak. In this case, the fine structure of the $d s$ sample leads to many mixed voxels, i.e. voxels with a grey scale value between that of ice and air, and it is difficult to find a threshold value for segmentation. The optimum threshold was determined by fitting a sum of two Gaussian curves to the grey scale histograms and calculating the intersection of the individual Gaussians (Sonka et al., 1999). This procedure minimizes the number of spurious voxels introduced in the segmentation process. The optimum threshold was determined for each tomogram, and the mean for each class was finally applied to segment the images. In Fig. 4, bars indicate the variations around the mean optimum threshold for all measurements of a particular class. This uncertainty in threshold finally leads to an uncertainty in the SSA, where the sensitivity of SSA on threshold variations depends on the snow type and has to be determined experimentally. 
Table 2. Sample characteristics and preparation methods for the different snow types together with the results. $\rho_{\text {weighed }}$ is the snow density calculated after weighing a known volume, whereas $\rho_{\mathrm{CT}}$ is the density calculated from the segmented $\mu \mathrm{CT}$ images. Note that the relatively large density error includes both the measurement error and the natural sample variation. The number of adsorption and tomography measurements for each snow type corresponds to Nr. BET and Nr. $\mu \mathrm{CT}$ respectively. The given $\mathrm{SSA}_{\mathrm{BET}}$ and SSA $\mu$ CT represents the mean values -measured by each method- for each snow type and the errors are "interblock errors" (see Sect. 3). The SSA Type are the mean values of all measurements made on each snow with both methods. The given errors are the corresponding standard deviations $(1 \sigma)$.

\begin{tabular}{|c|c|c|c|c|c|c|c|c|c|}
\hline snow type & ICSSG & $\begin{array}{l}\text { snow } \\
\text { history }\end{array}$ & $\begin{array}{c}\rho_{\text {weighed }} \\
\mathrm{g} \mathrm{cm}^{-3}\end{array}$ & $\begin{array}{c}\rho_{\mathrm{CT}} \\
\mathrm{g} \mathrm{cm}^{-3}\end{array}$ & $\begin{array}{l}\text { Nr. } \\
\text { BET }\end{array}$ & $\begin{array}{l}\mathrm{Nr} . \\
\mu \mathrm{CT}\end{array}$ & $\begin{array}{l}\mathrm{SSA}_{\mathrm{BET}} \\
\mathrm{cm}^{2} \mathrm{~g}^{-1}\end{array}$ & $\begin{array}{l}\mathrm{SSA}_{\mu \mathrm{CT}} \\
\mathrm{cm}^{2} \mathrm{~g}^{-1}\end{array}$ & $\begin{array}{l}\text { SSA }_{\text {Type }} \\
\mathrm{cm}^{2} \mathrm{~g}^{-1}\end{array}$ \\
\hline$d s$ & $2 \mathrm{a}$ & 8 days @ $-50{ }^{\circ} \mathrm{C}$ & $0.11( \pm 0.01)$ & $0.11( \pm 0.02)$ & 4 & 11 & $616( \pm 29)$ & $665( \pm 73)$ & $642( \pm 51)$ \\
\hline$m I$ & $3 a(2 a)$ & 14 days @ $-17^{\circ} \mathrm{C}$ & $0.15( \pm 0.01)$ & $0.13( \pm 0.01)$ & 5 & 13 & $346( \pm 11)$ & $420( \pm 27)$ & $381( \pm 42)$ \\
\hline$m I I$ & $3 a$ & 17 days @-3 ${ }^{\circ} \mathrm{C}$ & $0.19( \pm 0.05)$ & $0.19( \pm 0.03)$ & 5 & 12 & $270( \pm 31)$ & $291( \pm 27)$ & $282( \pm 30)$ \\
\hline$d h$ & $5 a_{2}$ & field, not sieved & $0.31( \pm 0.02)$ & $0.31( \pm 0.02)$ & 5 & 14 & $93( \pm 5)$ & $91( \pm 6)$ & $92( \pm 6)$ \\
\hline$w s$ & $6 a$ & field, sieved & $0.54( \pm 0.03)$ & $0.56( \pm 0.03)$ & 3 & 9 & $49( \pm 1)$ & $48( \pm 3)$ & $48( \pm 2)$ \\
\hline
\end{tabular}

\section{Results}

For each of the $m I, m I I$, and $d h$ types five blocks were investigated, whereas for $d s$ and $w s$ only four and three blocks, respectively, were used. Thus, 22 adsorption measurements were made, of which 15 were accompanied by three $\mu \mathrm{CT}$ scans, and the remaining seven by two, giving a total of $59 \mu \mathrm{CT}$ images.

\subsection{Adsorption of methane}

The mean heat of adsorption $\left(\Delta Q_{\mathrm{CH}_{4}}\right)$ can be used as a test for the reliability of the measurement (Legagneux et al., 2002; Dominé et al., 2007b). It is derived according to $\Delta Q_{\mathrm{CH}_{4}}=R T_{C} \ln C$, using the BET constant $C$ (Legagneux et al., 2002; Gregg and Sing, 1982). From the whole set of measurements, we found a mean value of 2680 $( \pm 200) \mathrm{J} \mathrm{mol}^{-1}$. This value is in agreement with the one recommended by Dominé et al. (2007b), who give 2540 $( \pm 200) \mathrm{J} \mathrm{mol}^{-1}$, and confirms the reliability of our measurements.

As briefly mentioned by Legagneux et al. (2004), the adsorption of methane on the sample holder walls leads to an artefact in the BET analysis. Dominé et al. (2007b) explained that it produces a systematic overestimation of the SSA but can be easily corrected by measuring the adsorption isotherm on the wall of the sample holder. The amount of methane that adsorbed on the wall of the sample holder was quantified by blank measurements. We found that $0.278( \pm 0.001) \mathrm{m}^{2}$ has to be subtracted from the measured total snow surface area to correct for this artefact. In our case, the contribution of the wall makes up to 8 to $30 \%$ of the total uptake of methane, the more important contribution occurring for coarse snow, which has a low SSA.

This correction will also affect the measured heat of adsorption. Indeed, in the case of non corrected results, the given heat of adsorption convolutes the heat release related to adsorption on the snow and also that related to adsorp- tion on the sample holder. The resulting heat of adsorption is therefore a weighted average of the two contributions. We quantified the heat of adsorption on the wall of our Polyethyleneimine/Stainless steel sample holder to be 1760 $( \pm 150) \mathrm{J} \mathrm{mol}^{-1}$. As already mentioned by Dominé et al. (2007b), because the heat released due to the adsorption on the wall of the sample holder is smaller than that released due to the adsorption on the snow, the corrected value of $\Delta Q_{\mathrm{CH}_{4}}$ is higher than the uncorrected. For a detailed description of the significance of $\Delta Q_{\mathrm{CH}_{4}}$ we invite the reader to refer to Chaix et al. (1996), Chaix and Dominé (1997) and Legagneux et al. (2002). The effect of wall adsorption on the $\Delta Q_{\mathrm{CH}_{4}}$ value is also explained in detail in Dominé et al. (2007b).

The heat of adsorption value given at the beginning of this section $\left(\Delta Q_{\mathrm{CH}_{4}}=2680( \pm 200) \mathrm{J} \mathrm{mol}^{-1}\right)$ as well as all the SSA values given here are corrected for adsorption on the wall of the sample holder.

SSA values measured in this study range from $48( \pm 1)$ to $656( \pm 52) \mathrm{cm}^{2} \mathrm{~g}^{-1}$. As described in section 2.2.3, the errors on each value were calculated from both the inherent errors of the experimental apparatus and the errors on physicochemical data. This specific type of error was called "a-priori error". The calculated mean SSA values for each snow type are given in Table 2, where the cited errors are the standard deviations $(1 \sigma)$ of all measurements within each snow type. This error was called "interblock error".

\subsection{Tomography}

The SSA values determined by tomography ranged between $46( \pm 1)$ and $733( \pm 78) \mathrm{cm}^{2} \mathrm{~g}^{-1}$. In contrast to the BET measurements, where one measurement was taken for one block of snow, several measurements, using different subsamples, have been made for each snow block (see Sect. 2.1). The error on SSA for one individual block is the standard deviation $(1 \sigma)$ of the SSA determined from the different subsamples taken from one single block. This type of error, 


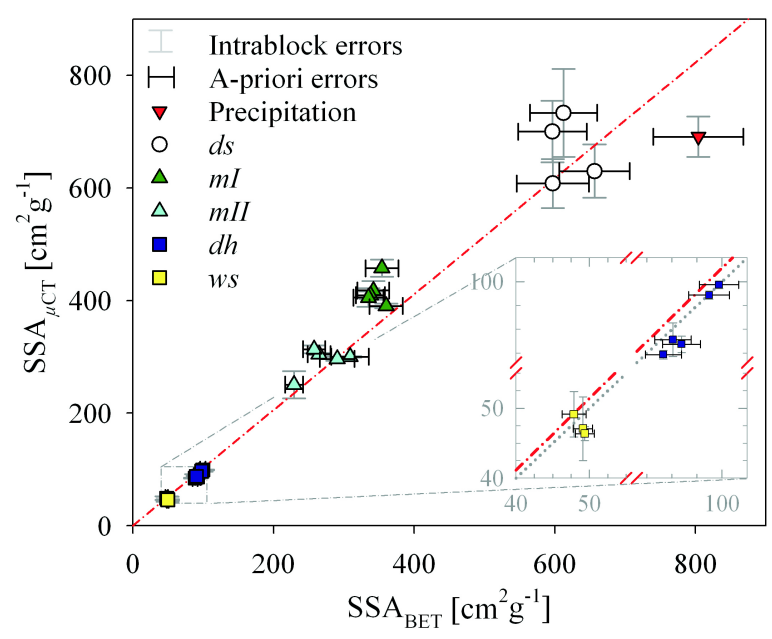

Fig. 5. The correlation between adsorption measurements and tomography was found to be $\mathrm{SSA}_{\mu} \mathrm{CT}=1.03( \pm 0.03) \mathrm{SSA}_{\mathrm{BET}}$. The plotted error bars given for the adsorption method were called "apriori errors" whereas the one given for tomography were called "intrablock errors" (see text for details). The data point called "Precipitation" was not taken into account when calculating the correlation coefficient as explained in Sect. 3.3. The results for the samples $\mathrm{dh}$ and $w s$ are magnified in the insert, where the dash-dot line represents the calculated correlation and the dot line, the 1:1 line.

and the average SSA, were called "intrablock error" and "intrablock SSA", respectively, and are compared to the adsorption results in Fig. 5. The summarized mean SSA values, calculated from the average of all subsamples for each snow type are given in Table 2, where the cited errors are the "interblock errors" (defined in Sect. 3.1). For decomposing snow ( $d s$ in Fig. 5), there is a wide variation among the different subsamples of each of the 4 blocks (e.g. from 672 to $821 \mathrm{~cm}^{2} \mathrm{~g}^{-1}$ within one block). Note that in Fig. 5 the mean (intrablock) SSA is shown, and the variation is expressed in the large error bars. Also, within one and the same subsample, the SSA varies between $5 \%$ and $10 \%$ depending on the position of the investigated subvolume. As Fig. 4 illustrates, the optimum threshold varies notably for the different decomposing snow measurements, and, in addition, the SSA depends heavily on the threshold for this type $\left(\approx 0.10 \mathrm{~cm}^{2} \mathrm{~g}^{-1}\right.$ per grey scale unit). Thus, each individual SSA measurement for decomposing snow has an uncertainty of about $\pm 57 \mathrm{~cm}^{2} \mathrm{~g}^{-1}$ due to the uncertainty in the optimum threshold determination. In this light, the possible error introduced by the marching cubes algorithm when extracting the surface (Flin et al., 2005) plays only a minor role. This error appears as an artefact of digitization, and becomes only relevant when the resolution limit is approached. For example, for a sphere of radius 5 voxel our algorithm overestimates the specific surface area by $3.4 \%$. We therefore assume that the segmentation process is much more critical for the introduction of errors than the surface extraction. How- ever, as this possibly systematic error is smaller than the one estimated from the standard deviation, we chose the standard deviation as error estimate. On the other hand, the coarse types can be segmented with less ambiguity, thus yielding a sharply determined threshold, and are less sensitive to threshold variation (e.g. for ws, $\approx 0.002 \mathrm{~cm}^{2} \mathrm{~g}^{-1}$ per grey scale unit). Therefore, the uncertainty for $w s$ measurements, for example, due to thresholding is only $\pm 0.5 \mathrm{~cm}^{2} \mathrm{~g}^{-1}$ for each individual sample. Also, for all other snow types other than decomposing snow, the spatial variation within one scan is less pronounced, i.e. typically about $2 \%$.

\subsection{Comparison of data}

The correlation between SSA values measured by adsorption of methane ( $\left.\mathrm{SSA}_{\mathrm{BET}}\right)$ and $\mu \mathrm{CT}$ values $\left(\mathrm{SSA}_{\mu \mathrm{CT}}\right)$ was found to be very good. Indeed, the slope of the correlation line, which is shown on Fig. 5, was found to be $\mathrm{SSA}_{\mu \mathrm{CT}}=1.03( \pm 0.03) \mathrm{SSA}_{\mathrm{BET}}$. This result was obtained by forcing the linear regression through the origin and assigning a weight to each data point equal to the inverse of the product of the "intrablock errors" on $\mathrm{SSA}_{\mu \mathrm{CT}}$ and the "a-priori errors" on SSA $\mathrm{BET}_{\text {B }}$. This procedure was motivated by the fact that the errors change with the SSA. We note that the correlation is better for lower SSA, which is in agreement with the evolution of the errors on measurements. Moreover, the obtained SSA values are consistent with most recent measurements (Dominé et al., 2007b) on comparable snow samples.

Albeit the correlation between both methods is very good, the small deviations may be attributed to inherent errors of each method, which are discussed in the following paragraphs.

Concerning the adsorption measurements, two major sources of error are suspected.

i) The molecular area of methane $\left(a_{\mathrm{CH}_{4}}\right)$ was experimentally obtained from the molecular area of nitrogen (Chaix et al., 1996). Nonetheless, there is no absolute value of the molecular area of a nitrogen molecule $\left(a_{\mathrm{N}_{2}}\right)$, when it is adsorbed on ice. This is mainly due to its dependence on the nature of the surface, on which it is adsorbed. Therefore it cannot be defined better than within $\approx 5-10 \%$ (Gregg and Sing, 1982). Hence, the value for the molecular surface area of methane used here $\left(1.92 \times 10^{-19} \mathrm{~m}^{2}\right)$ also suffers from at least $5-10 \%$ uncertainty, which will influence the calculation of SSA.

ii) An error of $1 \mathrm{~K}$ in the liquid nitrogen temperature determination will give rise to a difference of $\approx 200 \mathrm{~Pa}$ in $P_{0}$ at a temperature close to the boiling point of liquid nitrogen. From error propagation we estimate an error of about $\approx 3 \%$ in the SSA.

Regarding the $\mu \mathrm{CT}$ measurements, the three main sources of error are:

i) Setting the threshold value as discussed in Sect. 3.2.

ii) Air inclusions in the ice, which could lead to an overestimation of the SSA compared to adsorption, since these 
pores are not accessible for methane during an adsorption measurement. Analyzing the tomograms, the contribution of such inclusions to the total surface area was found to be always lower than $0.6 \%$, thus being negligible.

iii) Choosing a resolution, which is not sufficient to grasp the finest structures of the snow. This would lead to an underestimation of SSA compared to adsorption. Since our values for the finest investigated snow were even slightly above the adsorption values, it may be concluded that structure sizes for this snow type are still of the same order of magnitude as the resolution $(10 \mu \mathrm{m}$ voxel size, corresponding to roughly $30 \mu \mathrm{m}$ resolution).

To check this hypothesis and to find a limit for the resolution, we gathered and immediately measured solid precipitation, obtaining an adsorption value of $804( \pm 64)$ and a tomography value of $691( \pm 36) \mathrm{cm}^{2} \mathrm{~g}^{-1}$. It indicates that precipitation particles still feature structures below about $30 \mu \mathrm{m}$, which can be resolved by the gas adsorption method, but not with the resolution of our $\mu \mathrm{CT}$; we state therefore that for snow the resolution limit of this $\mu \mathrm{CT}$ is approximately $700 \mathrm{~cm}^{2} \mathrm{~g}^{-1}$. A theoretical upper limit is given by the SSA of $30 \mu \mathrm{m}$ cubes, i.e. $2000 \mathrm{~cm}^{2} \mathrm{~g}^{-1}$; however, the geometry and distribution of sizes in real structures reduces this theoretical value. Therefore, no theoretical justification for our experimentally found upper limit can be given. Note that this data point, denoted as "Precipitation" in Fig. 5, was not included in the calculation of the correlation coefficient because the $\mu \mathrm{CT}$ value is probably too low due to insufficient resolution.

Apart from the instrumental and analysis issues, also the sampling procedure could have induced artefacts. It is well known that a too small sample holder could compress the boundary layer, or break away grains at the boundary. This would lead to an overestimation or underestimation, respectively, of the weighed density with respect to the density obtained from segmented tomograms. Table 2 shows no significant systematic deviation, however.

\section{Discussion}

\subsection{Comparison of methods}

Previous studies of the SSA of presumably comparable samples using adsorption method and computer tomography had provided results in the same order of magnitude. For example, Dominé et al. (2007b) measured, using adsorption of methane, the SSA of rounded grains ranging from 118 to $382 \mathrm{~cm}^{2} \mathrm{~g}^{-1}$ with a mean value for the 32 samples of $206( \pm 74) \mathrm{cm}^{2} \mathrm{~g}^{-1}$. Schneebeli and Sokratov (2004) used similar snow for their experiments and measured SSAs of 122 and $218 \mathrm{~cm}^{2} \mathrm{~g}^{-1}$.

However, as no direct comparison between both methods has ever been made, it is difficult to assess the quality of methods to determine the SSA of snow. Here, we present the first direct comparison of methods based on two different physical processes and find an agreement within $3 \%$ between the SSA values measured by adsorption of methane $\left(\mathrm{SSA}_{\mathrm{BET}}\right)$ and $\mu \mathrm{CT}\left(\mathrm{SSA}_{\mu \mathrm{CT}}\right)$, for snow having an SSA below $700 \mathrm{~cm}^{2} \mathrm{~g}^{-1}$. This shows that the adsorption of methane and the absorption of X-ray light allow measuring reliably the SSA of snow. It also proves that the data previously obtained using both methods do not suffer from artefacts, such as a lack of resolution or deeper issues, such as problems with physical concepts (e.g. the unknown size of adsorbed methane molecules on the ice surface).

Nonetheless, we showed in Sect. 3.2, that for SSAs higher than around $700 \mathrm{~cm}^{2} \mathrm{~g}^{-1}$, tomography underestimates SSA. In Dominé et al. (2007b), 11\% out of a total of 345 SSA measurements were over $700 \mathrm{~cm}^{2} \mathrm{~g}^{-1}$. When considering only the 68 measurements made on freshly fallen snow, $46 \%$ of the measurements exceed this value. On the other hand, we can consider the evolution of the SSA of natural snow as a function of temperature for isothermal metamorphism or under a temperature gradient by using the parameterization suggested by Taillandier et al. (2007). For example, if we choose a snow sample having a typically high initial SSA of $1000 \mathrm{~cm}^{2} \mathrm{~g}^{-1}$, we can estimate that it will take only 4,9 , 18 or $29 \mathrm{~h}$ under temperature gradient conditions at a mean temperature of evolution of the snow layer of $-5,-10,-15$ and $-20^{\circ} \mathrm{C}$, respectively, for the SSA to decrease to below $700 \mathrm{~cm}^{2} \mathrm{~g}^{-1}$. In the case of isothermal metamorphism, the times are $7,12,19$ or $28 \mathrm{~h}$ respectively for temperatures of $-5,-10,-15$ and $-20^{\circ} \mathrm{C}$. Therefore, these estimations show that the SSA of fresh snow rapidly, i.e. within one day, drops into a regime accessible with a $\mu$ CTḦowever, directly after precipitation, there is a short time span where our $\mu \mathrm{CT}$ is not suited to measure the SSA of snow; this is true for 31 out of 64 fresh snow samples collected by Dominé et al. (2007b). It has to be emphasized that this is not a problem of the tomographic method per se, because a better resolution would solve the problem.

Since three of our snow types evolved from the same snow under known conditions, we can check the validity of the parameterisation on our snow samples. The SSA (SSA Type) obtained on our $d s$ snow sample was considered as the initial SSA and the times and temperatures given in Table 2 were used in the parameterization. The calculated SSA values are $337 \mathrm{~cm}^{2} \mathrm{~g}^{-1}$ for $m I$ and $260 \mathrm{~cm}^{2} \mathrm{~g}^{-1}$ for $m I I$. Those results agree within $12 \%$ and $8 \%$, respectively, with the one, which we measured, and show that the parameterization is consistent with our measurements and that the times, to reach an SSA of $700 \mathrm{~cm}^{2} \mathrm{~g}^{-1}$, given above are reasonable.

\subsection{Time scales involved in surface smoothing}

Our measurements not only show the coincidence between both methods, but also prove experimentally that our snow samples were smooth up to about $30 \mu \mathrm{m}$. This means that structures smaller than $30 \mu \mathrm{m}$ are probably absent in 


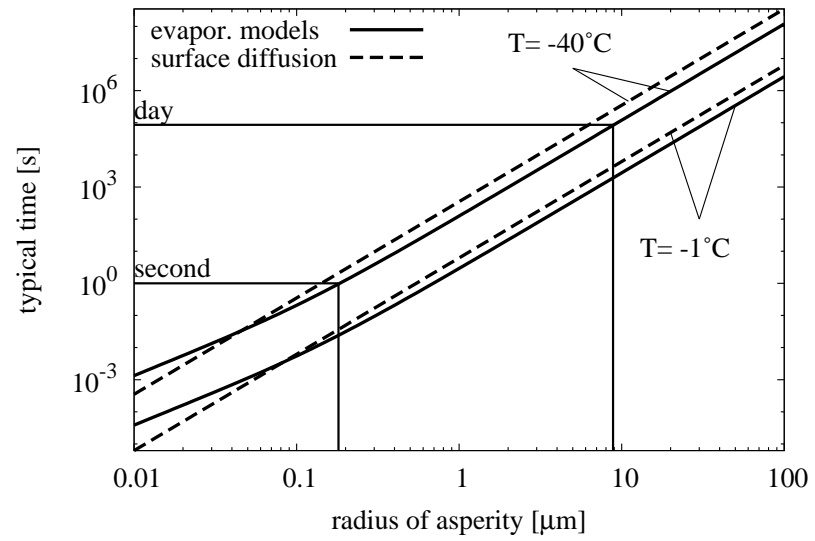

Fig. 6. Characteristic time for the smoothing of an ice surface due to the Kelvin effect (straight lines) and surface diffusion (dashed lines) as a function of the initial radius of the asperity.

metamorphosed snow or if present, do not contribute to the SSA. This finding is not in contradiction with the measurements made by Wergin et al. (2002), as they argue that the irregular hexagonal crystal which they observed generally measure 60 to $90 \mu \mathrm{m}$ across. Our aim in this section is to estimate time scales involved in surface smoothing i.e. the life time of an asperity, of the size of some $10 \mu \mathrm{m}$ and less, on an ice surface. We do not pretend providing a model which can be used to simulate the evolution of the snowpack but the provided equations can be successfully used to estimate the evolution of the size of asperities-if they are present-while, for instance, preparing or measuring snow samples.

Two mechanisms may be capable of smoothing the ice surface and therefore would explain our experimental results: vapour transport due to the Kelvin effect (Flin et al., 2003; Legagneux and Dominé, 2005), and surface diffusion. The latter process might be quite fast on the ice surface due to the presence of a highly mobile surface layer, often called premelt layer or quasi liquid layer (e.g. Dash et al., 2006).

\subsubsection{Role of the Kelvin effect}

To evaluate the role of the Kelvin effect in smoothing out an asperity, we consider a simple configuration i.e.: a half sphere emerging from a flat surface. The higher water vapour pressure above the curved surface as compared to the flat surface results in sublimation of the curved asperity where the water vapour is transported away by gas phase diffusion. Even for such a simple configuration, the kinetics of how the half sphere will sublimate would require a numerical simulation. As such a calculation is far beyond the scope of this paper, we simplify the geometry and neglect the flat surface where the half sphere rests. Considering only a flat surface at an infinite distance from the half sphere, an analytical solution for this diffusion problem can be obtained. The effect of a flat surface underneath the half sphere is an increase of the pressure gradient, implying an increase of the diffusion flux. In this sense our estimation yields an upper limit for the diffusion time. For the estimate, we assume that the radius of the asperity -and therefore the water vapour flux from the evaporating asperity under steady state conditions- is constant and that the asperity has disappeared when the amount of water it contained has diffused away. A detailed explanation of the calculations is found in the Appendix B. The result of the estimate is shown in Fig. 6. The same calculation was performed also considering two different ways of evolution of the radius (increase and decrease) but as the three different considerations coincide very well (Kerbrat et al., 2007), those calculations are not presented here.

\subsubsection{Role of the surface diffusion}

The effect of surface diffusion on the smoothing of asperities may be estimated by calculating the order of magnitude of the time it takes to smear out the asperity by the random movement of molecules on the highly mobile surface. The surface diffusion constant $D_{s}$ has been determined in the past in a number of different experiments, but the results depend heavily on the method and on the temperature range of the measurement (Mizuno and Hanafusa, 1987; Brown and George, 1996; Livingston et al., 1997; Jung et al., 2004). Here, we use the work of Mizuno and Hanafusa (1987), since they measured the properties in the quasi liquid layer on a collection of small ice beads at temperatures close to the melting point, which resembles the situation in snow. Using NMR spectroscopy between -1.5 and $-20^{\circ} \mathrm{C}$, they found an activation energy of $E_{a}=0.24 \mathrm{eV}$ and a preexponential factor of $D_{0}=8.43 \times 10^{-9} \mathrm{~m}^{2} \mathrm{~s}^{-1}$.

Using these assumptions, and the characteristic diffusion length of $\Delta x=\left(4 D_{s} t_{d}\right)^{1 / 2}$, we can estimate the characteristic time $t_{d}$ to distribute an asperity of radius $R$ into a disc of thickness $d$

$t_{d}=\frac{R^{3}}{6 d D_{s}}$.

To estimate an upper limit for the timescale, we consider that the asperity is completely smeared out when it has reached the thickness of the quasi-liquid layer. However, measurements of the thickness of the quasi-liquid layer are subject to discrepancies. The fact that the techniques used to measure it are sensitive to different physical features of the quasi-liquid layer could explain the differences (Huthwelker et al., 2006). Several theoretical models related to the quasi-liquid layer have also been developed (Dash et al., 2006), but the experimental discrepancies prevent from easily deciding which model is the most appropriate. Moreover, it has been shown theoretically that impurities (Wettlaufer, 1999) and curvature (Baker and Dash, 1989) could affect the thickness of the quasi-liquid layer. Hence, the thickness of this layer is not yet exactly established. In this paper our aim is only to evaluate the effect of surface diffusion 
when flattening an ice surface. Thus, in the calculation, we use an order of magnitude assumption for the quasi-liquid layer thickness, in agreement with published data. Hence, in Fig. 6, the thickness of the quasi-liquid layer was set to 100 and 10 namometer at $-1{ }^{\circ} \mathrm{C}$ and $-40^{\circ} \mathrm{C}$, respectively. For such thicknesses, the characteristic time for the surface diffusion is 10 times higher, but becomes comparable to vapour diffusion for smaller radii, where the size of the asperity is comparable to the mean free path and diffusion becomes limited by molecular kinetics (Pruppacher and Klett, 1997).

4.3 Comparison of the estimate with the experimental observations

Figure 6 suggests that even at temperatures as low as $-40^{\circ} \mathrm{C}$ the 'smoothing' of the surface due to the Kelvin effect is very fast, and after a day structures of the size of several micrometers can disappear. This estimate agrees with our measurements. Indeed, if we used Eq. (B6) to calculate the size of the asperities which would still be present on our $d s$ sample which was stored 8 days at $-50^{\circ} \mathrm{C}$, we find that all asperities having a radius lower than $15 \mu \mathrm{m}$ may have sublimated. This radius corresponds to an asperity of a about $30 \mu \mathrm{m}$ in size, which is the resolution of the tomograph. As no asperities smaller than the resolution of the tomograph may have "survived"-if they were present after the formation of the

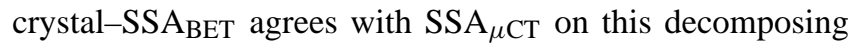
snow sample.

In the case of the sample called "Precipitation" (see Sect. 3.3), the latter was measured about one hour after the precipitation. The air temperature during sampling was $\approx-7^{\circ} \mathrm{C}$. Using Eq. (B6), we calculated that only asperities with a diameter of about $20 \mu \mathrm{m}$ and smaller would have had time to sublimate before the measurement. This means that on the 'Precipitation' sample there possibly were still asperities which could not be resolved by the tomograph and therefore $\mathrm{SSA}_{\mathrm{BET}}$ was higher than $\mathrm{SSA}_{\mu \mathrm{CT}}$.

The calculation also shows that during the scan of a sample, which takes $3 \mathrm{~h}$ and which is made at $-15^{\circ} \mathrm{C}$ (see Sect. 2.3), all asperities with a diameter of $\approx 25 \mu \mathrm{m}$ which may have been present at the beginning of the scan will disappear during the measurement. As this value is lower than the resolution of the tomograph, the changes occurring during the scan will not affect the results. Note that in the case of an adsorption measurement, there is no evolution of the sample during the measurement, as it is done at liquid nitrogen temperature.

4.4 Remark concerning the smoothness on a molecular scale

We saw in the previous paragraphs that the surface of ice is very likely to be smooth on a micrometer and nanometer scale. Nevertheless, ice is a high vapour pressure $\left(P_{\mathrm{ice}}^{0}\right)$ solid and in thermodynamic equilibrium, its surface is continuously bombarded with water molecules with a rate of $j_{\text {kin }}=P_{\text {ice }}^{0} \bar{v} /\left(4 k_{B} T\right)$ with the mean thermal velocity $\bar{v}=\left(8 k_{B} T / \pi M\right)^{1 / 2}$, while the same flux of water molecules desorbs. In absence of surface diffusion on the ice surface, this continuous exchange of molecules with the gas phase could lead to a molecularly rough surface. However, driven by the minimization of the surface energy, the roughness will disappear, if surface diffusion is fast enough. The interplay between absorption, desorption and diffusion is complex and has been subject to molecular dynamics studies. Xiao and Ming (1994) studied this interplay and found conditions for the molecules smoothness of surfaces. Based on their work and using the activation energy of diffusion of $E_{a}=0.24 \mathrm{eV}$ (Mizuno and Hanafusa, 1987), the ice surface should be also smooth on a molecular scale, as long as the ice does not grow.

\subsection{Practical aspects}

Both techniques are suitable to measure reliably the SSA of snow. The measurements require in all cases a relatively constant temperature and A.C. power supply. For the adsorption method, liquid nitrogen must be available, but the measurement can be done at room temperature and does not require a cold laboratory contrary to the $\mu \mathrm{CT}$. The application in the field is therefore limited to sites with a relatively good infrastructure. As an alternative, $\mu \mathrm{CT}$ samples may be cast in the field and quenched in iso octane or decane, for instance, to avoid any evolution of the sample, and brought into a cold lab to be scanned. Snow for the adsorption method can be sampled in the holder and stored in liquid nitrogen until the measurement.

The cost of investment to build an adsorption measurement device is far lower than a $\mu \mathrm{CT}$ device but each measurement requires liquid nitrogen and single use sealing gaskets.

Nevertheless, it has to be pointed out here that for many purposes optical methods may be more appropriate for field work. Matzl and Schneebeli (2006), for instance, use near infrared photography to map the SSA of a snow pit wall, and Painter et al. (2007), using contact spectroscopy, determine the optical grain size, which can be related to SSA.

4.6 Sampling volume, macroscale resolution and snow stratigraphy

Methane adsorption measures the smallest naturally occurring ice particles. Compared to tomography, this independence of resolution is its largest advantage. However, snowpacks are layered (Colbeck, 1991). In fact, the traditional classification of snow layers underestimates the vertical variation of snow properties substantially (Pielmeier and Schneebeli, 2003) . This is also the case for SSA (Matzl and Schneebeli, 2006). A high vertical spatial resolution is therefore extremely important to understand the exchange processes in a natural snowpack. Methane adsorption works only on a relatively large volume; in our measurements we used a sampling 
volume of $286.5 \mathrm{~cm}^{3}$, compared to $0.144 \mathrm{~cm}^{3}$ for tomography. Therefore it is difficult to resolve the SSA of thin layers with methane adsorption, although Legagneux et al. (2002) have reported to have done this by scraping a thin layer into their sample holder. The use of methane adsorption measurements in simulations of real snowpacks must carefully consider errors introduced by the large sampling volume. This is especially important when photon flux and permeability are calculated.

\subsection{Atmospheric implications}

It is well established that ice-air interactions play an important role for the composition of the atmosphere above snowpacks (Grannas et al., 2007; Dominé et al., 2007a; Dominé and Shepson, 2002). The total amount of ice surface areai.e. the SSA-which is available for heterogeneous reactions is of great importance when developing models for air - ice interactions within and above snowpacks. However, in such case, the transport of reactive trace gases through porous snow, is also of key importance. In the absence of wind pumping, the transport of trace gases depends on the interplay of advection in the gas phase, local adsorption, and the gas phase diffusion through the highly porous snow (Dominé et al., 2007a). Modeling these coupled transport processes is difficult, especially, as experimental data on thermodynamic and kinetic quantities governing these individual processes, are scarce. Up to now, only few measurements have been done to study the transport of gases through snow and have been analyzed using empirical or semi-empirical equations (e.g. Albert and Shultz, 2002; Herbert et al., 2006). In the case of inert gases i.e. which do not interact with the ice surface, the effective speed of transport through the snow can be calculated from the diffusivity of the compound in air, the porosity of the snowpack and its tortuosity (Schwarzenbach et al., 2003; Herbert et al., 2006). While the porosity can be easily calculated from a density measurement, tortuosity is a parameter, which is somehow difficult to assess (Albert and Shultz, 2002), but which could be easily retrieved from tomographic measurements. However, the low resolution of the instruments used with respect to the molecular scale let the question open whether the structure measured by $\mu \mathrm{CT} \mathrm{s}$ could be used when considering molecular flows. This point is getting even more important when the molecules considered adsorb on the ice surface of the snow crystal while being transported into or out of the snowpack. In this study, we show that for most of the snow types, the amount of ice accessible for trace gases could be measured using a $\mu \mathrm{CT}$ with $30 \mu \mathrm{m}$ resolution. Therefore, the 3 -D structure measured by the $\mu \mathrm{CT}$ can be successfully used to develop models of the diffusivity of trace gases in snow.

Finally, the water vapour fluxes responsible for the smoothing of the surface after the snow crystal has stopped growing may also influence the partitioning of atmospheric trace gases between the gas and the adsorbed phase within and over the snow pack. Indeed, on the first hand, trace gases, which may have been trapped during the crystal growth (Huthwelker, 1999; Kärcher and Basko, 2004), could be released during the surface flattening. Such a mechanism would lead to a transport of atmospheric gases from the higher to the lower atmosphere. On the other hand, some could be trapped where ice is growing and therefore would be removed from the gas phase also modifying the atmospheric composition over the snowpack.

\section{Conclusions}

For the first time ever, we have compared the performance of two techniques to measure the SSA of snow. Although the two techniques used are based on two different physical concepts, the correlation factor between both methods was found to be $1.03( \pm 0.03)$, for SSA values ranging between 50 and $700 \mathrm{~cm}^{2} \mathrm{~g}^{-1}$. The spatial resolution of the adsorption method is on the molecular level, while the effective resolution of the $\mu \mathrm{CT}$ is about $30 \mu \mathrm{m}$. Thus, the very good agreement between both measurements show that any micrometer or nanometer sized surface structures which would remain undetected with the $\mu \mathrm{CT}$, do not contribute significantly to the SSA. Consequently, our measurements prove that the ice surface in an alpine snow pack is essentially smooth up to a scale of about $30 \mu \mathrm{m}$. In contrast, the differences between the two techniques for SSA values larger than $700 \mathrm{~cm}^{2} \mathrm{~g}^{-1}$ supports previous observations that such microstructures are present in fresh snow.

From simple estimations of the time scales for sublimation (Kelvin effect) and surface redistribution (diffusion in a quasi-liquid layer) of small asperities we draw the conclusion that both processes are capable of smoothing the surface on a length scale of about $30 \mu \mathrm{m}$ within a few hours. This has also implications for the evolution of ice prepared in the laboratory for heterogeneous chemistry experiments in that annealing leads to a molecularly flat surface.

The absence of surface micro- and nanostructures is significant for the modelling in such diverse fields as friction on snow, snow chemistry, snow optics, and snow metamorphism. In modelling snow metamorphism, for example, a smooth surface allows to ignore all processes which might occur on a scale smaller than a few micrometers.

Another very important implication of these results is that the reliability of the $\mu \mathrm{CT}$ in capturing the geometry of aged snow is guaranteed. This fact is crucial for further investigations to link physical properties with the geometry of snow, for which the $\mu \mathrm{CT}$ is an ideally suited device. The adsorption method remains nonetheless more adapted to measure very fresh snow. 


\section{Appendix A}

\section{Equations for the analysis of the adsorption measurements}

\section{A1 Number of adsorbed molecules}

The number of molecules adsorbed on the ice surface after the $n$-th injection of methane in unit of molecules $\mathrm{g}^{-1}$ is given by

$$
\begin{aligned}
& N_{\mathrm{ads}_{n}}=\left\{V_{i} \sum_{k=1}^{n}\left(\frac{P_{k}^{\prime}}{T_{h_{k}}^{\prime}}-\frac{P_{k}}{T_{h_{k}}}\right)\right. \\
& \left.-P_{n}\left(\frac{V_{e h}}{T_{h_{n}}}+\frac{V_{d}}{T_{c}}\right)\right\} \frac{A}{m_{\text {ice }} R},
\end{aligned}
$$

(Legagneux et al., 2002) where the signification of each symbol is given in Table 1 .

\section{A2 Error on the SSA}

The specific surface area is obtained from the BET transform (see Fig. 2) and Eq. (1) and is given by

$$
\mathrm{SSA}=\mathrm{N}_{\mathrm{M}} \times \mathrm{a}_{\mathrm{CH}_{4}} .
$$

The error on the SSA is therefore given by

$\Delta \mathrm{SSA}=\operatorname{SSA}\left(\frac{\Delta N_{\mathrm{M}}}{N_{\mathrm{M}}}+\frac{\Delta a_{\mathrm{CH}_{4}}}{a_{\mathrm{CH}_{4}}}\right)$,

where $\Delta N_{\mathrm{M}}$ result from error while fitting Eq. (1) to the BET transform. Having

$N_{\mathrm{M}}=\frac{1}{S+I}$,

where $S$ and $I$ are the slope and the intercept, respectively of the BET transform, $\Delta N_{\mathrm{M}}$ is given by,

$$
\Delta N_{\mathrm{M}}=\frac{\Delta S}{S^{2}}+\frac{\Delta I}{I^{2}} .
$$

\section{Appendix B}

\section{Diffusion due to Kelvin effect}

In this section, we present the equations to estimate the time it takes to evaporate a small spherical particle due to the Kelvin effect, if the transport of vapour is limited by gas phase diffusion. In the following paragraphs, we consider a semi-infinite environment, which means that all quantities refer to a half sphere. We consider a particle sitting on a flat surface, which is assumed not to interact with the gas phase. Under this assumption, and assuming steady state diffusion, the water vapour pressure field over the half sphere may be approximated by the solution of the diffusion equation in spherical symmetry which is:

$p(r)=p_{\infty}+\frac{A}{r}$.

The Kelvin effect states that over a convex surface the vapour pressure is higher than over a flat surface, which provides the boundary conditions

$p(R)=p_{\infty} \exp \left(\frac{C}{R}\right)$

$C=\frac{2 m_{\mathrm{H}_{2} \mathrm{O} \sigma} \sigma}{k_{\mathrm{B}} T \rho_{\text {ice }}}$.

where $\sigma$ means surface tension, $\rho_{\text {ice }}$ is the density of ice, and $m_{\mathrm{H}_{2} \mathrm{O}}$ is the mass of one water molecule. This determines the constant $A=R p_{\infty}\left[\exp \left(\frac{C}{R}\right)-1\right]$. In thermodynamic equilibrium, the diffusion away from the curved surface is given by Fick's law, $j=(D / k B T)\left(A / R^{2}\right)$, which, upon multiplication with the surface of a half sphere, gives the particle flux leaving the sphere

$J(R)=2 \pi \frac{D}{k \mathrm{~B} T} R p_{\infty}\left[\exp \left(\frac{C}{R}\right)-1\right]$.

Then, the rate of mass loss due to diffusion may be expressed as

$\frac{d m}{d t}=-m_{\mathrm{H}_{2} \mathrm{O}} J(R)$.

If we now neglect the changing radius during sublimation, i.e. assume a constant diffusion rate. The time it takes for a half sphere to evaporate can be calculated from the analytical solution of Eq. B5 as

$t=\frac{\gamma}{3} \frac{R^{2}}{\left[\exp \left(\frac{C}{R}\right)-1\right]}$,

$\gamma=\frac{\rho_{\text {ice }} k_{\mathrm{B}} T}{m_{\mathrm{H}_{2} \mathrm{O}} D p_{\infty}}$.

The asperity is considered as disappeared when its total mass has been diffused.

The diffusion constant has been corrected for kinetic effects for very small spheres, as described in Pruppacher and Klett (1997).

Acknowledgements. The authors thank M. Birrer for designing and producing the sample holder for the adsorption measurements, T. Bartels-Rausch for constructing the BET apparatus and F. Dominé and L. Legagneux for advising during its construction. We also thank D. Schmid for her help during the campaign. This project is supported by the Swiss National Science Foundation, project no. 200021-108219. M. Kerbrat and B. Pinzer contributed equally to the work.

Edited by: T. Koop 


\section{References}

Adamson, A. W. and Dormant, L. M.: Adsorption of Nitrogen on Ice at 78 Degrees K, J. Am. Chem. Soc., 88, 2055-2057, 1966.

Adamson, A. W., Dormant, L. M., and Orem, M.: Physical Adsorption of Vapors on Ice. I. Nitrogen, J. Colloid Interface Sci., 25, 206-217, 1967.

Albert, M. R. and Shultz, E. F.: Snow and firn properties and airsnow transport processes at Summit, Greenland, Atmos. Environ., 36, 2789-2797, 2002.

Baker, M. B. and Dash, J. G.: Charge-Transfer in Thunderstorms and the Surface Melting of Ice, J. Cryst. Growth, 97, 770-776, 1989.

Bartels-Rausch, T., Eichler, B., Zimmermann, P., Gäggeler, H. W., and Ammann, M.: The adsorption enthalpy of nitrogen oxides on crystalline ice, Atmos. Chem. Phys., 2, 235-247, 2002,

http://www.atmos-chem-phys.net/2/235/2002/.

Bartels-Rausch, T., Guimbaud, C., Gäggeler, H. W., and Ammann, M.: The partitioning of acetone to different types of ice and snow between 198 and 223 K, Geophys. Res. Lett., 31, L16110, doi:10.1029/2004GL020070, 2004.

Brown, D. E. and George, S. M.: Surface and Bulk Diffusion of $\mathrm{H}_{2}{ }^{18} \mathrm{O}$ on Single-Crystal $\mathrm{H}_{2}{ }^{16} \mathrm{O}$ Ice Multilayers, J. Phys. Chem., 100, 15 460-15 469, 1996.

Brunauer, S., Emmett, P. H., and Teller, E.: Adsorption of gases in multimolecular layers, J. Am. Chem. Soc., 60, 309-319, 1938.

Chaix, L. and Dominé, F.: Effect of the thermal history of ice crushed at $77 \mathrm{~K}$ on its surface structure as determined by adsorption of $\mathrm{CH}_{4}$ at low surface coverage, J. Phys. Chem. B, 101, 6105-6108, 1997.

Chaix, L., Ocampo, J., and Dominé, F.: Adsorption of $\mathrm{CH}_{4}$ on laboratory-made crushed ice and on natural snow at $77 \mathrm{~K}$. Atmospheric implications, C. R. Acad. Sci., Ser. II, 322, 609-616, 1996.

Colbeck, S., Akitaya, E., Armstrong, R., Gubler, H., Lafeuille, J., Lied, K., McClung, D., and Morris, E.: The International Classification for Seasonal Snow on the Ground, Int. Comm. On snow and Ice of the Int. Assoc. of Sci. Hydrol., Wallingford, Oxon, UK, 1990.

Colbeck, S. C.: The layered character of snow covers, Rev. Geophys., 29, 81-96, 1991.

Coléou, C., Lesaffre, B., Brzoska, J. B., Ludwig, W., and Boller, E.: Three-dimensional snow images by X-ray microtomography, Ann. Glaciol., 32, 75-81, 2001.

Dash, J. G., Fu, H. Y., and Wettlaufer, J. S.: The Premelting of Ice and Its Environmental Consequences, Rep. Prog. Phys., 58, 115-167, 1995.

Dash, J. G., Rempel, A. W., and Wettlaufer, J. S.: The physics of premelted ice and its geophysical consequences, Rev. Mod. Phys., 78, 695-741, 2006.

Dominé, F. and Shepson, P. B.: Air-snow interactions and atmospheric chemistry, Science, 297, 1506-1510, 2002.

Dominé, F., Cabanes, A., Taillandier, A. S., and Legagneux, L.: Specific surface area of snow samples determined by $\mathrm{CH}_{4}$ adsorption at $77 \mathrm{~K}$ and estimated by optical, microscopy and scanning electron microscopy, Environ. Sci. Technol., 35, 771-780, 2001.

Dominé, F., Lauzier, T., Cabanes, A., Legagneux, L., Kuhs, W. F., Techmer, K., and Heinrichs, T.: Snow metamorphism as revealed by scanning electron microscopy, Microsc. Res. Tech., 62, 33-
48, 2003.

Dominé, F., Albert, M., Huthwelker, T., Jacobi, H. W., Kokhanovsky, A. A., Lehning, M., Picard, G., and Simpson, W. R.: Snow physics as relevant to snow photochemistry, Atmos. Chem. Phys., 8, 171-208, http://www.atmos-chem-phys. net/8/171/2008/, 2008a.

Dominé, F., Taillandier, A. S., and Simpson, W. R.: A parameterization of the specific surface area of seasonal snow for field use and for models of snowpack evolution, J. Geophys. Res., 112, F02031, doi:10.1029/2006JF000512, 2007.

Dullien, F. A. L.: Porous Media: Fluid Transport and Pore Structure, Academic Press Inc.,U.S., second edn., 1992.

Fassnacht, S. R., Innes, J., Kouwen, N., and Soulis, E. D.: The specific surface area of fresh dendritic snow crystals, Hydrol. Process., 13, 2945-2962, 1999.

Flanner, M. G. and Zender, C. S.: Linking snowpack microphysics and albedo evolution, J. Geophys. Res., 111, D12208, doi:10.1029/2005JD006834, 2006.

Flin, F., Brzoska, J. B., Lesaffre, B., Cileou, C., and Pieritz, R. A.: Full three-dimensional modelling of curvature-dependent snow metamorphism: first results and comparison with experimental tomographic data, J. Phys. D: Appl. Phys., 36, A49-A54, 2003.

Flin, F., Brzoska, J. B., Lesaffre, B., Coleou, C. C., and Pieritz, R. A.: Three-dimensional geometric measurements of snow microstructural evolution under isothermal conditions, Ann. Glaciol., 38, 39-44, 2004.

Flin, F., Brzoska, J. B., Coeurjolly, D., Pieritz, R. A., Lesaffre, B., Coléou, C., Lamboley, P., Teytaud, O., Vignoles, G. L., and Delesse, J. F.: Adaptive estimation of normals and surface area for discrete 3-D objects: Application to snow binary data from X-ray tomography, IEEE Trans. Image Process., 14, 585-596, doi:10.1109/TIP.2005.846021, 2005.

German, R. M.: Sintering Theory and Practice, John Wiley \& Sons, Inc., 1996.

Granberg, H.: Distribution of grain sizes and internal surface area and their role in snow chemistry in a sub-Arctic snow cover, Ann. Glaciol., 7, 149-152, 1985.

Grannas, A. M., Jones, A. E., Dibb, J., Ammann, M., Anastasio, C., Beine, H. J., Bergin, M., Bottenheim, J., Boxe, C. S., Carver, G., Chen, G., Crawford, J. H., Dominé, F., Frey, M. M., Guzmán, M. I., Heard, D. E., Helmig, D., Hoffmann, M. R., Honrath, R. E., Huey, L. G., Hutterli, M., Jacobi, H. W., Klán, P., Lefer, B., McConnell, J., Plane, J., Sander, R., Savarino, J., Shepson, P. B., Simpson, W. R., Sodeau, J. R., von Glasow, R., Weller, R., Wolff, E. W., and Zhu, T.: An overview of snow photochemistry: evidence, mechanisms and impacts, Atmos. Chem. Phys., 7, 43294373, http://www.atmos-chem-phys.net/7/4329/2007/, 2007.

Gregg, S. J. and Sing, K. S. W.: Adsorption, Surface Area and Porosity, Academic Press Limited, London, second edn., 1982.

Grenfell, T. C. and Warren, S. G.: Representation of a nonspherical ice particle by a collection of independent spheres for scattering and absorption of radiation, J. Geophys. Res., 104, $31697-$ 31 709, doi:10.1029/1999JD900496, 1999.

Henson, B. F., Voss, L. F., Wilson, K. R., and Robinson, J. M.: Thermodynamic model of quasiliquid formation on $\mathrm{H}_{2} \mathrm{O}$ ice: Comparison with experiment, J. Chem. Phys., 123, 2005.

Herbert, B. M. J., Halsall, C. J., Jones, K. C., and Kallenborn, R.: Field investigation into the diffusion of semi-volatile organic compounds into fresh and aged snow, Atmos. Environ., 40, 
1385-1393, doi:10.1016/j.atmosenv.2005.10.055, 2006.

Hoff, J. T., Gregor, D., Mackay, D., Wania, F., and Jia, C. Q.: Measurement of the specific surface area of snow with the nitrogen adsorption technique, Environ. Sci. Technol., 32, 58-62, 1998.

Huthwelker, T.: Experimente und Modellierung der Spurengasaufnahme in Eis, Cuvillier Verlag, Göttingen, 1999.

Huthwelker, T., Ammann, M., and Peter, T.: The Uptake of Acidic Gases on Ice, Chem. Rev., 106, 1375-1444, 2006.

Jellinek, H. G. and Ibrahim, S. H.: Sintering of Powdered Ice, J. Colloid Interface Sci., 25, 245-254, 1967.

Jung, K. H., Park, S. C., Kim, J. H., and Kang, H.: Vertical diffusion of water molecules near the surface of ice, J. Chem. Phys., 121, 2758-2764, 2004.

Kaempfer, T. U., Schneebeli, M., and Sokratov, S. A.: A microstructural approach to model heat transfer in snow, Geophys. Res. Lett., 32, L21503, doi:10.1029/2005GL023873, 2005.

Kärcher, B. and Basko, M. M.: Trapping of trace gases in growing ice crystals, J. Geophys. Res., 109, D22204, doi:10.1029/2004JD005254, 2004.

Kerbrat, M., Pinzer, B., Huthwelker, T., Gäggeler, H. W., Ammann, M., and Schneebeli, M.: Measuring the specific surface area of snow with X-ray tomography and gas adsorption: comparison and implications for surface smoothness, Atmos. Chem. Phys. Discuss., 7, 10287-10322, http://www. atmos-chem-phys-discuss.net/7/10287/2007/, 2007.

Kokhanovsky, A. A. and Zege, E. P.: Scattering optics of snow, Appl. Opt., 43, 1589-1602, 2004.

Legagneux, L. and Dominé, F.: A mean field model of the decrease of the specific surface area of dry snow during isothermal metamorphism, J. Geophys. Res., 110, F04011, doi:10.1029/2004JF000181, 2005.

Legagneux, L., Cabanes, A., and Dominé, F.: Measurement of the specific surface area of 176 snow samples using methane adsorption at $77 \mathrm{~K}, \mathrm{~J}$. Geophys. Res., 107, 4335-4349, doi:10.1029/2001JD001016, 2002.

Legagneux, L., Taillandier, A. S., and Dominé, F.: Grain growth theories and the isothermal evolution of the specific surface area of snow, J. App. Phys., 95, 6175-6184, 2004.

Libbrecht, K. G.: The physics of snow crystals, Rep. Prog. Phys., 68, 855-895, 2005.

Lide, D. R.: CRC Handbook of Chemistry and Physics, Taylor and Francis, Boca Raton, FL, 86th edn., 2006.

Lied, A., Dosch, H., and Bilgram, J. H.: Surface Melting of Ice $\mathrm{I}_{h}$ Single-Crystals Revealed by Glancing Angle X-Ray-Scattering, Phys. Rev. Lett., 72, 3554-3557, 1994.

Livingston, F. E., Whipple, G. C., and George, S. M.: Surface and bulk diffusion of HDO on ultrathin single-crystal ice multilayers on Ru(001), J. Chem. Phys., 108, 2197-2207, 1997.

Matzl, M. and Schneebeli, M.: Measuring specific surface area of snow by near-infrared photography, J. Glaciol., 52, 558-564, 2006.
Mizuno, Y. and Hanafusa, N.: Studies of surface properties of ice using nuclear magnetic resonance, J. Phys., 48, 511-517, 1987.

Moussa, M. R., Muijlwij.R, and Vandijk, H.: Vapour Pressure of Liquid Nitrogen, Physica, 32, 900-912, 1966.

Murphy, D. M. and Koop, T.: Review of the vapour pressures of ice and supercooled water for atmospheric applications, Q. J. R. Meteorol. Soc., 131, 1539-1565, doi:10.1256/qj.04.94, 2005.

Narita, H.: Specific surface of deposited snow II, Low Temp. Sci., 29, 69-81, 1971.

Ohser, J. and Mücklich, F.: Statistical Analysis of Microstructures in Materials Science, John Wiley \& Sons, Inc., 2000.

Painter, T. H., Molotch, N. P., Cassidy, M., Flanner, M., and Steffen, K.: Contact spectroscopy for determination of stratigraphy of snow optical grain size, J. Glaciol., 53, 121-127, 2007.

Pielmeier, C. and Schneebeli, M.: Stratigraphy and changes in hardness of snow measured by hand, ramsonde and snow micro penetrometer: a comparison with planar sections, Cold Reg. Sci. Technol., 34, 393-405, 2003.

Pruppacher, H. R. and Klett, J. D.: Microphysics of clouds and precipitation, Kluwer Academic Publishers, 1997.

Rango, A., Wergin, W. P., and Erbe, E. F.: Snow crystal imaging using scanning electron microscopy: I. Precipitated snow, Hydrol Sci., 41, 219-233, 1996.

Schneebeli, M. and Sokratov, S. A.: Tomography of temperature gradient metamorphism of snow and associated changes in heat conductivity, Hydrol. Process., 18, 3655-3665, 2004.

Schneebeli, M., Pielmeier, C., and Johnson, J. B.: Measuring snow microstructure and hardness using a high resolution penetrometer, Cold Reg. Sci. Technol., 30, 101-114, 1999.

Schwarzenbach, R. P., Gschwend, P. M., and Imboden, D. M.: Environmental Organic Chemistry, John Wiley \& Sons, Inc., New York, 2003.

Sommerfeld, R. A. and Rocchio, J. E.: Permeability Measurements on New and Equitemperature Snow, Water Resour. Res., 29, 2485-2490, 1993.

Sonka, M., Hlavac, V., and Boyle, R.: Image Processing: Analysis and Machine Vision, Thomson-Engineering, second edn., 1999.

Taillandier, A. S., Dominé, F., Simpson, W. R., Sturm, M., and Douglas, T. A.: Rate of decrease of the specific surface area of dry snow: Isothermal and temperature gradient conditions, J. Geophys. Res., 112, F03003, doi:10.1029/2006JF000514, 2007.

Wergin, W. P., Rango, A., Foster, J., Erbe, E. F., and Pooley, C.: Irregular snow crystals: Structural features as revealed by low temperature scanning electron microscopy, Scanning, 24, 247256, 2002

Wettlaufer, J. S.: Impurity effects in the premelting of ice, Phys. Rev. Lett., 82, 2516-2519, 1999.

Xiao, R. F. and Ming, N. B.: Surface Roughening and SurfaceDiffusion in Kinetic Thin-Film Deposition, Phys. Rev. E, 49, 4720-4723, 1994 